\title{
Mother-calf relationships and maternal investment in European bison Bison bonasus
}

\author{
Katarzyna DALESZCZYK
}

\begin{abstract}
Daleszczyk K. 2004. Mother-calf relationships and maternal investment in European bison Bison bonasus. Acta Theriologica 49: 555-566.

Mother-young relationships, up to the third month of the calves' life, were investigated in European bison Bison bonasus (Linnaeus, 1758) from Białowieża National Park breeding centres (Poland). During the first week, calves spent most of their time close to their mothers and were rarely seen in the vicinity of other group members. Highest suckling rate, most frequent vocal contact and agonistic behaviour of mothers towards intruders, were other characteristics of this period. Although being a forest species, European bison exhibit a following type of strategy for offspring protection, typical for ungulates living in open areas; no hiding phase was observed. Suckling rates were similar in calves of both sexes, however, the pattern of nursing was different: male calves suckled longer, but in rarer bouts than female calves. The mothers' condition, reflected by their social rank, did not influence the suckling rate. No sex differences were recorded in other maternal activities or mother-calf distance. The presumption of a lack of sex-biased maternal investment in European bison is confirmed by the results of other research.

Mammal Research Institute, Polish Academy of Sciences, 17-230 Białowieża, Poland; e-mail: kdalesz@bison.zbs.bialowieza.pl
\end{abstract}

Key words: Bison bonasus, maternal care, hiding-following, maternal investment

\section{Introduction}

In mammals, the survival and development of offspring depend to a great degree on the quality of mother-young relationships. Ungulates are precocial species in which neonates are well developed and able to move independently soon after birth (Lent 1974); this demands an especially efficient strategy for offspring protection. In this group of mammals, two major categories of mother-infant relationships or tactics of predator avoidance (Fisher et. al. 2002) are recognized, namely hiding and following. The main behavioural difference is the degree of association between mother and young during the first days of life (Ralls et al. 1986). In all ungulates parturition is followed by a post-partum phase, lasting 1-20 hours, when intensive interaction between the mother and neonate takes place (Lent 1974). After that, a considerable divergence occurs. In hider type species, which live primarily in forested areas, infants remain concealed in vegetation cover, isolated from both predators and conspecifics. The distance from the mother ranges from $30 \mathrm{~m}$ to 1 
$\mathrm{km}$, depending on the species (Lent 1974). During the hiding stage contact between mother and offspring is limited to short periods of nursing and care. Hiding functions as a strategy to avoid predation (Lent 1974, Fisher et. al. 2002). In contrast, in followers, a type associated mainly with open habitats, young stay close to their mothers from birth and frequent contact between them is a rule. Protection against predation is achieved by maternal defence (Lent 1974).

There has been a considerable discussion on which sex of offspring is more costly to raise (eg Trivers and Willard 1973, Clark 1978, Caley and Nudds 1987, Byers and Moodie 1990, Kojola 1998, Hewison and Gaillard 1999). In species with polygynous mating systems a bias in maternal investment towards sons was predicted, as in males variance in reproductive success is higher and depends on their competitive ability (Trivers and Willard 1973). Some data on ungulate species confirmed this hypothesis, but others did not (eg Caley and Nudds 1987, Byers and Moodie 1990, Cassinello 1996, reviews in Kojola 1998 and Hewison and Gaillard 1999). According to Byers and Moodie (1990), extra investment in male offspring may be limited in ungulates as mothers already have to support high growth rates.

The European bison Bison bonasus (Linnaeus, 1758) is a forest dweller with a polygynous mating system. Data on mother-calf interactions collected in free-ranging herds are only fragmentary (Wróblewski 1927; Caboń-Raczyńska et al. 1987) but it appears that the young are not hidden. Precociousness at birth is a basic adaptation in the follower system (Estes and Estes 1979). European bison exhibit this characteristic (Daleszczyk and Krasiński 2001). The other representative of genus Bison, American bison Bison bison lives in open habitat and belongs to followers (eg Green 1992b). No information on maternal investment in European bison has been found in literature. Data on sex differences in maternal investment in American bison are equivocal (Rutberg 1986, Green and Rothstein 1991). It seems impossible to conduct a detailed study on maternal care in free-living European bison because of the closed habitat, as well as the aggressiveness and wariness of cows with young calves. Nevertheless, patterns of mother-offspring relationships are known to be retained in captivity (Ralls et al. 1986). In my study, carried out on captive European bison from Białowieża National Park, I addressed two main subjects: (1) classifying the type of mother-calf relationships performed by European bison; and (2) determining whether mothers show sex-biased maternal investment in this species.

\section{Material and methods}

\section{Animals studied}

Research was conducted at European bison captive breeding and show centres in Białowieża National Park, Poland, from July 1998 to October 2000. Eleven mother-calf pairs were observed from birth to the 14th week of calf's life. The sample included 7 female calves and 4 male calves. Groups containing observed pairs consisted of 1 bull, 3-11 cows and 1-6 calves. 
In the show centre the section for European bison comprises 6.14 ha and is divided into 4 adjacent enclosures, partly covered with trees. During visiting hours the bison group stays in one enclosure, outside visiting hours the animals have access to $2-3$ enclosures. In the breeding centres the size of enclosures range from 3.64 to 30.60 ha. The area is mostly covered with mixed coniferous forest, with glades serving as pastures. During the vegetation growing season bison feed on natural vegetation, supplemented by crushed grain according to individual demands. In winter, bison are fed on hay, beetroot and crushed grain.

\section{Data collection}

Observations were conducted from dawn to dusk and during long summer days alternately from dawn to midday and from midday to dusk constituting a whole observation day out of two successive days. All observations took place from the outside of the enclosures by using 8 x 30 binoculars when necessary. Subjects were observed every day in the first week of the calf's life and one day a week during the rest of research period. Instantaneous scan samples were conducted at 5-minute intervals to note the type of activity performed by observed individuals and the distance between the calf and other bison in a group (see below). Data on maternal behaviour (nursing, licking, vocalization, aggression towards intruders) were collected using focal animal sampling (Altmann 1974). Up to four pairs were observed simultaneously. Total observation time of one pair averaged $196 \mathrm{~h}$. For comparison purposes, additional data on the activity pattern of two barren cows was collected (instantaneous scan sampling as above, $372 \mathrm{~h}$ of observations per cow).

Distance between observed animals was estimated by a comparison with the body length of an adult bison. Three distance categories were adopted with regard to mother-calf proximity: 0-3 m, 4-10 $\mathrm{m},>10 \mathrm{~m}$. To examine spatial relations between calves and bison other than their mothers, only the frequency of the first category was recorded. A distance of up to $3 \mathrm{~m}$ was chosen based on earlier observations of captive European bison. Subordinate-dominant interactions took place when the animals involved were about 1-2 $\mathrm{m}$ from each other. On the other hand, resting bison were most often noted within $3 \mathrm{~m}$ from the nearest group member and neighbours were not chosen at random but distinct preferences/avoidances were revealed (K. Daleszczyk, unpubl.). A distance of about $3 \mathrm{~m}$ was assumed to be an important boundary in the social interactions of European bison, with a second boundary of $10 \mathrm{~m}$ chosen arbitrarily.

According to Walther (1979), hider and follower species may be easily discriminated by the distance between mother and calf when lying. The number of minutes mother and infant were lying within one mother-length divided by the total minutes both pair members were lying (data from the first week) gave Walther's measure (Ralls et al. 1986).

To describe activity pattern and activity synchrony, the following terms were used: (1) Resting: includes lying and standing without foraging. (2) Maternal care: includes nursing and licking calf outside nursing. (3) Activity of observed animals was considered to be synchronized when both individuals (a) rested, (b) foraged, or (c) walked without foraging.

With regard to nursing, the following measures were recorded: duration of nursing bouts, time intervals between successive nursing bouts, licking/sniffing calves by their mothers during nursing, and whether mother or calf initiated and terminated the first sucking period within a given nursing bout. One nursing bout included all periods of sucking activity of a calf not interrupted by more than 15 successive minutes (Clutton-Brock et al. 1982). The total suckling time recorded in a given period divided by the total observation time formed the suckling rate. The mother was assumed to initiate nursing when it was directly preceded by her vocalizing, approaching, or nosing her calf. Mother terminated nursing when she walked away or lay down before her calf stopped sucking. The calf was assumed to initiate nursing when it approached its mother and started to suck or when it made the lying mother stand up and begin suckling. It was not always possible to determine univocally which individual initiated or terminated the nursing bout. Because of that and the frequency of nursing bouts decreasing with calves' age, analyses of these parameters were based on months of life and included eight pairs, for which data was collected for at least seven nursing bouts in each period. Social hierarchy among cows was determined based on aggressive interactions (Lott 1974) during earlier observations. 


\section{Data analysis}

Wherever possible, repeated-measure ANOVA (RMANOVA) was used to analyse conformity of parameter changes within each mother-calf pair, and if not stated otherwise, results of RMANOVA are given in the text. The weeks of a calf's life were grouped as follows: $1,2-3,4-5,6-7,8-9,10-11,12-14$, and the mean for each pair in each period were repeated measures. Two pairs were omitted from these analyses because data were not available in all periods. One-way ANOVA was performed to investigate sex differences in duration and frequency of nursing. $\chi^{2}$-test was used for comparison of frequencies. Prior to parametric analyses, data were tested for normality and transformed appropriately if necessary. Two-tailed statistical tests were used throughout. All analyses were performed using STATISTICA software (StatSoft 1984-2003).

\section{Results}

Mothers of male and female calves did not differ with regard to their age (10.5 and 8.1 years, respectively, Mann-Whitney $U$-test: $U=9.50, n_{1}=4, n_{2}=7, p=$ 0.40 ), so this parameter could not have been responsible for any sex bias in maternal behaviour.

\section{Distance between calf and other bison}

During week 1, calves spent $68 \%$ of observation time within $3 \mathrm{~m}$ from their mothers, considerably more than in other weeks $\left(F_{6,48}=16.35, p<0.0001\right)$, and were seldom recorded further than $10 \mathrm{~m}$ from them (Fig. 1). The older the calves were, the more time they spent further from their mothers. No difference in the

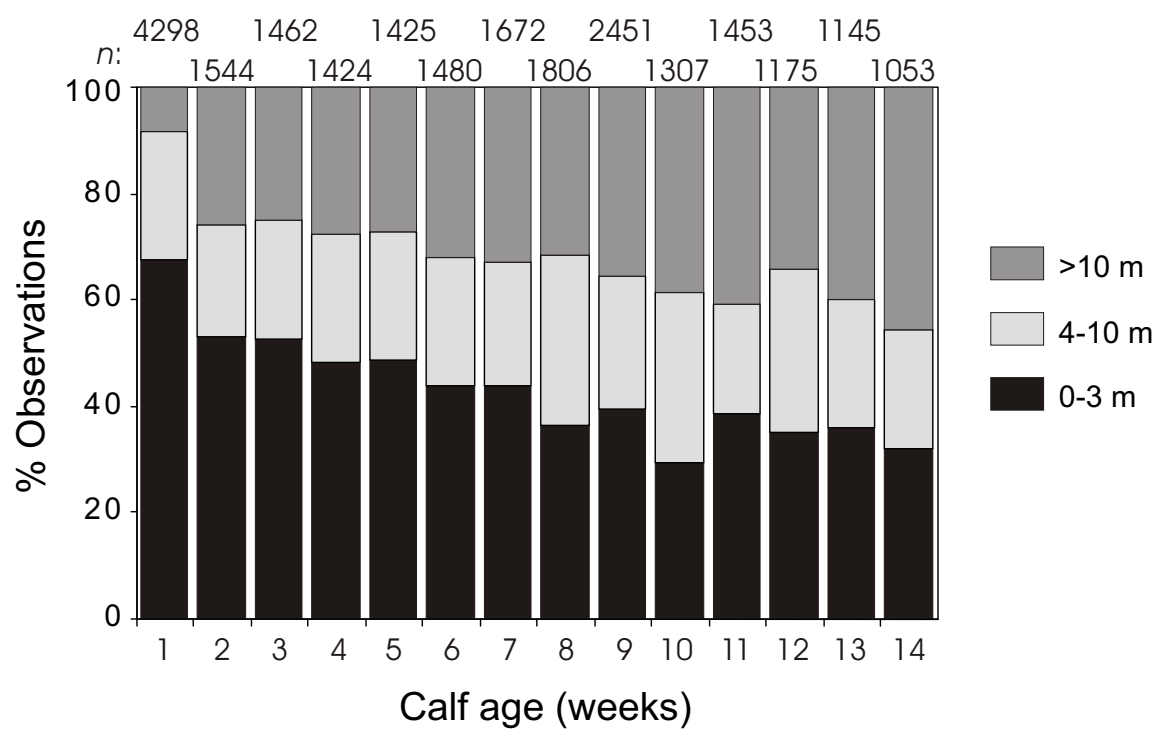

Fig. 1. Mean percentage of scan samples in which mothers and calves were at various distances from each other, in relation to calves' age. Sample size $(n)$ is given above each column. 
mother-calf distance was found between mother-daughter and mother-son pairs $\left(F_{1,7}=0.86, p=0.38\right)$. Walther's measure for week 1 averaged $75 \%$.

In spatial relations of calves with other group members, week 1 also differed significantly. Calves were recorded within $3 \mathrm{~m}$ from their peers for $12 \%$ of time then in comparison to an average of $54 \%$ in weeks $2-14\left(F_{6,36}=19.76, p<0.0001\right)$, and for $6 \%$ and $25 \%$ of time, respectively, from adult bison other than the calves' own mothers $\left(F_{6,36}=3.60, p=0.007\right)$.

\section{Maternal care}

Suckling rate decreased with calves' age, with the value in week 1 being significantly greater than in the following weeks $\left(F_{6,48}=6.29, p<0.0001\right.$, Fig. 2$)$. There was no difference in average suckling rate during the first 3 months between mothers ranked first or second in the social hierarchy $(n=5)$ and mothers of a lower social status ( $n=6$ ) (Mann-Whitney $U$-test: $U=13.00, p=0.72$ ), or between mothers with first-second calf $(n=4)$ and multiparous cows $(n=7)(U=8.00, p=$ 0.26 ). Frequency of nursing was the highest in weeks 1-3 (ANOVA: $F_{13,876}=12.94$, $p<0.0001)$. During the study period males suckled longer but in rarer bouts than females (mean length of nursing bouts: 7 and 5.5 min respectively, ANOVA: $F_{1,938}$ $=39.57, p<0.0001$; mean length of intervals between bouts: 116 and 98 min respectively, ANOVA: $\left.F_{1,888}=15.29, p<0.0001\right)$. However, the sex of calves did not influence the suckling rate $\left(F_{1,7}=1.13, p=0.32\right)$.

During the entire study period, mothers initiated less than a half of the nursing bouts and terminated most of them (Fig. 3). Frequency of nursing bouts initiated by

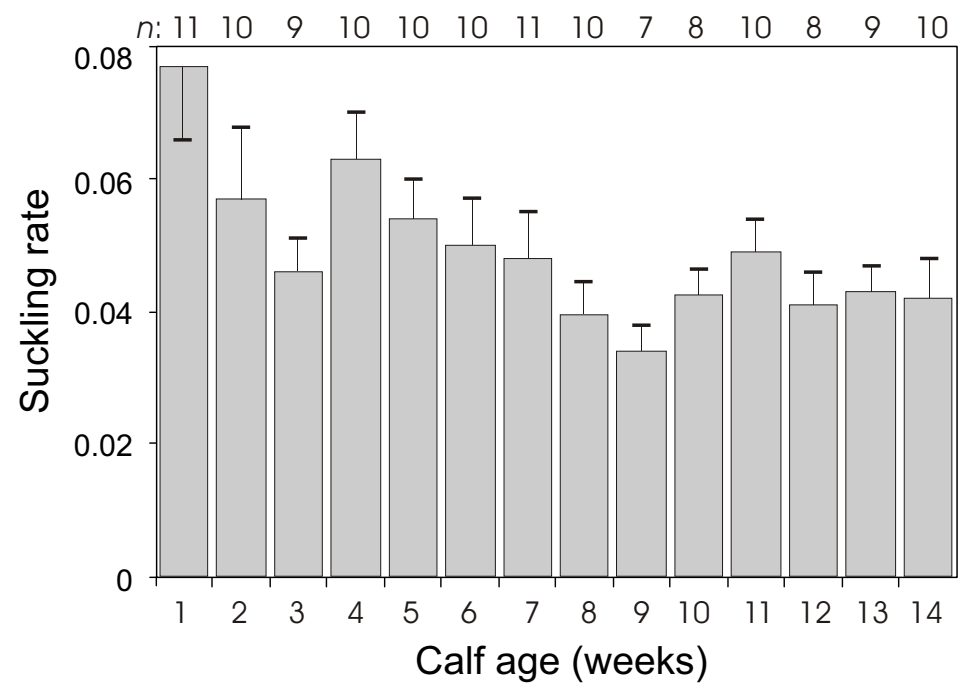

Fig. 2. Suckling rates in relation to calves' age. Vertical bars represent SE. Sample size $(n)$ is given above each column. 


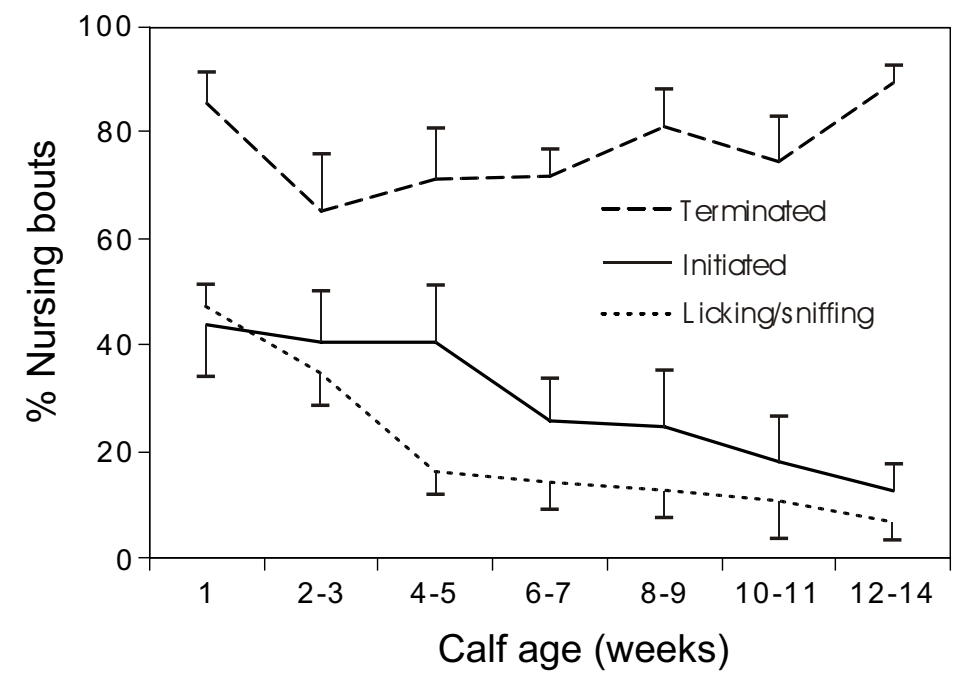

Fig. 3. Mean percentage of nursing bouts initiated and terminated by mothers, and mean percentage of nursing bouts during which mothers licked/sniffed their calves, in relation to calves' age. Vertical bars represent SE. Sample sizes were as follows: for initiating: 11, 9, 10, 9, 11, 11, 10; for terminating and licking/sniffing: 11, 10, 11, 11, 11, 11, 10.

mothers decreased with calf age $\left(F_{2,14}=4.21, p=0.037\right)$ while percentage of nursing bouts terminated by mothers did not change significantly $\left(F_{2,14}=1.31, p=0.30\right)$. There was no difference between male and female calves (months $1,2,3$ respectively, initiating: $\chi_{1}^{2}=1.11,0.78,0.01$; terminating: $\chi^{2}{ }_{1}=0.96,1.99,1.03$; in all cases NS).

Other maternal behaviours recorded were: licking/sniffing the calf during nursing, aggressive behaviour of mothers towards intruders, and vocal contact. Aggressive behaviour included threats like shaking horns, charges and infrequent fights, and was directed towards people, other group members, and even birds and butterflies. During the first 3 months vocalization between pair members was limited to mothers' grunting. Calves vocalized extremely rarely. Licking/sniffing the calf during nursing, aggression and grunting of mothers were most often observed in week 1 and the frequency of records dramatically dropped with calf age (Spearman correlation: licking/sniffing: $r_{\mathrm{s}}=-0.54, n=136, p<0.0001$; aggression: $r_{\mathrm{s}}=-0.43, n=135, p<0.0001$; grunting: $r_{\mathrm{s}}=-0.50, n=117, p<0.0001$; Fig. 3, Fig. 4). Comparison of mothers with daughters and mothers with sons in week 1 gave no differences (ANOVA: licking/sniffing: $F_{1,9}=0.60, p=0.46$; aggression: $F_{1,9}$ $=0.05, p=0.83$; grunting: $F_{1,9}=2.91, p=0.12$ ).

\section{Mother's activity}

Compared with control barren cows, the time mothers spent on resting began to decrease no sooner than weeks $8-9$ (6-7 weeks: $\chi^{2}{ }_{1}=2.65, p<0.1 ; 8-9$ weeks: $\chi^{2}{ }_{1}=$ $20.64, p<0.0001$; Fig. 5A), so at least until then maternal care was performed at 


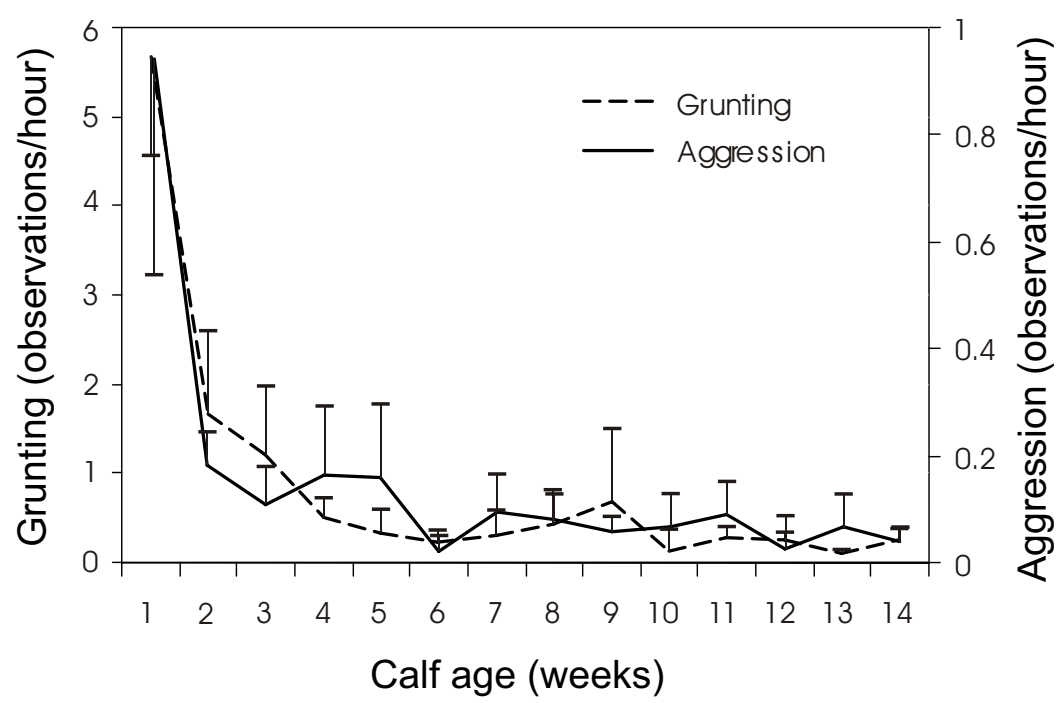

Fig. 4. Mean frequency in records of grunting and aggressive behaviour of mothers, in relation to calves' age. Vertical bars represent SE. Sample sizes were as follows: for grunting: $11,10,9,11,9,8,8$, $7,4,5,8,8,8,10$; for aggression: $11,10,9,11,10,10,11,11,6,7,11,9,9,10$.

(A)

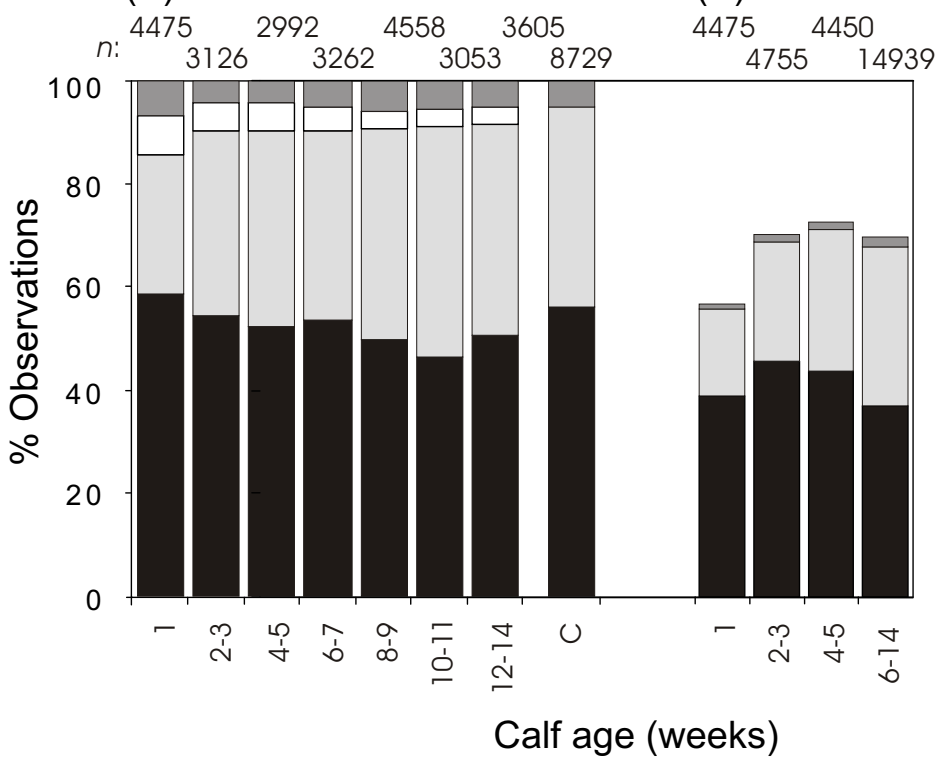

Other

Maternal care

Foraging

Resting

Fig. 5. Mean percentage of scans in which (A) mothers performed various types of activity, and (B) mothers synchronized various types of activity with the activity of other cows in a group, in relation to calves' age. For comparison, activity pattern of control barren cows ('C') is given. Sample size ( $n$ ) is given above each column. 
the cost of foraging. In week 1 time dedicated to maternal care reached a significantly higher value than in the following weeks $\left(F_{6,48}=9.25, p<0.0001\right.$; Fig. $\left.5 \mathrm{~A}\right)$, while foraging was especially limited $\left(F_{6,48}=4.49, p=0.001\right)$. Comparison throughout the study period between mothers with daughters and mothers with sons showed no difference with regard to maternal care $\left(F_{1,7}=1.23, p=0.30\right)$, but mothers of female calves foraged more than mothers of male calves $\left(F_{1,7}=5.82, p=0.047\right)$. Synchrony of mothers' activity with activities of other cows in a group was considerably lower in week 1 than in those following $\left(\chi^{2}{ }_{3}=102.46, p<0.0001\right.$; Fig.5B).

\section{Discussion}

\section{Mother-young relationships}

The general difference between the two strategies of offspring protection (hiding and following) is mother-infant distance and the frequency of mutual contacts during the first days after birth (Lent 1974). In European bison, week 1 was distinctly different from the following ones with regard to both spatial relations of calves with other group members and the intensity of their contacts with mothers. Calves spent then most time close to their mothers and other bison were seldom recorded in their vicinity. Keeping a young calf away from other group members helps it to learn its mother's scent, voice, and sight without being disturbed by other individuals (Egerton 1962). Such a situation may be achieved either by isolation of the mother-infant pair from the herd during and after parturition (Geist 1971, Lent 1974, Carl and Robbins 1988) or by maintaining a short distance between pair members and the aggressive behaviour of mother towards intruders, as recorded in the presented study (see also Egerton 1962). Extremely close distance between mother and calf in the first days of its life precludes any hiding phase in European bison. Similar changes in mother-calf distance and the considerable difference between weeks 1 and 2 were also found in American bison (Green 1992b).

Walther's measure (an index of mother-calf proximity) for follower species ranged from 65-100\% (Ralls et al. 1986). The index value for European bison falls within the same range and is almost identical with the result for American bison (72\%, Ralls et al. 1986). In hiders concealed infants are singly dispersed while in followers infants form peer groups early in their lives (McHugh 1958, Geist 1971, Estes and Estes 1979). The latter tendency was found in European bison after week 1.

Mothers initiated nursing bouts most frequently in the earliest period and the intervals between nursing bouts were shortest then. Frequent nursing meant frequent contact between mother and her offspring, typical of the follower strategy. From the beginning, calves initiated over half of the nursing bouts. In general, follower young are more likely to do this than hiders (Lent 1974).

Vocalization of mothers and their aggressive behaviour towards intruders were most pronounced in the earliest period in the calves' life. The behaviours did not 
seem to be a result of captive conditions as frequent grunting of cows with calves was also noted in free-living bison (Caboń-Raczyńska et al. 1987) and agonistic behaviour recorded in this study was more frequent in the cows from the closed breeding centres, where potential stress caused by captivity should be lower due to large forested enclosures and limited human presence. Very young ungulates are most vulnerable to predators and need the greatest protection. In European bison mothers of very young calves appear to be most aggressive so it seems that their anti-predator tactic is defence rather than hiding offspring. Older infants become fast, agile, and develop enough stamina to considerably increase their chances of escaping predator so they can rely more on other anti-predator tactics than mother defence (Geist 1971, Estes and Estes 1979, Green 1992a).

Predator avoidance was recognized as a main factor influencing the evolution of two alternative types of mother-infant relationships and the hypothesis about the association of following with open habitat was strongly supported in ungulates and macropods (Fisher et al. 2002). Large-bodied ungulate species were more likely to be followers, but the body size of the mother was not related to the type of maternal care when phylogenetic relationships were taken into account (Fisher et al. 2002). Gregarious ungulates were more likely to have evolved following behaviour although hider species included the same range of group sizes as follower species studied. In both ungulates and macropods, maternal care strategies were related to habitat structure independent of body size of mother or group size and according to the phylogenetic analysis in some clades of followers hiding has evolved in ungulate species that presently inhabit forest habitats (Fisher et al. 2002). Mother-infant interactions in European bison and American bison exhibit considerable similarities. Presumably the following type of mother-calf relationships evolved in the common ancestor of both species living in steppe and although a closer ancestor of European bison was already a forest form (Pucek 1986), following was retained in this species in spite of its closed habitat.

\section{Maternal investment}

Maternal investment in mammals was assessed using various measures, among them different estimates of milk intake, weight of offspring at birth or at weaning, and subsequent fecundity of mother (Byers and Moodie 1990). In ungulate females the greater part of reproduction costs is connected with lactation (Oftedal 1985), and nursing behaviour was reported to be a reliable indicator of milk intake in some species (Wettemann et al. 1978, Lavigueur and Barrette 1992). According to this, the highest maternal investment in European bison took place in week 1, as the level of suckling rates suggest. Although in male and female calves duration and frequency formed various nursing patterns, suckling rates did not differ between them. So if there were no sex differences in suckling efficiency, both longer but less frequent, and shorter but more frequent nursing bouts probably resulted in similar milk consumption. Although nursing efficiency may change with offspring age, as 
found in mule deer Odocoileus hemionus and mountain goats Oreamnos americanus, no sex differences were recorded in these species (Carl and Robbins 1988).

According to Trivers and Willard's (1973) hypothesis, in polygynous species, females in above average condition should invest more in sons than in daughters, as the future condition of sons' influences their reproductive success to a much higher degree than daughters. The rank within the social hierarchy may be used as an indirect estimate of mothers' condition (Clutton-Brock et al. 1984, Green and Rothstein 1991). In European bison the social status of a mother did not affect suckling rate. Presumably the higher social rank in bison cows is not coupled with important advantages like access to better forage as the food resources for grazers are distributed extensively rather than in patches, and so are difficult to be controlled by one or a few individuals. In American bison cows, the fitness benefits of a high social status were not identified (Rutberg 1983), and studies on this species did not support the Trivers-Willard hypothesis (Shaw and Carter 1989, Green and Rothstein 1991).

Time dedicated to maternal care was the same in European bison mothers with daughters or sons. Licking/sniffing to identify young during suckling allowed the dam to prevent suckling by the offspring of other cows. This is especially important during the neonatal period when milk is the only source of food for calves. No difference between male and female calves was recorded in this parameter or in the frequency of initiating and terminating nursing by mothers.

Proximity of calf and mother, together with the dam's aggressive behaviour towards intruders created a 'safe zone' for her calf during the time when calves were most vulnerable to injury by other bison. Vocal contact may be involved in maintaining this 'safe zone'. Vocalization served to initiate nursing, decrease mother-calf distance, and was frequently recorded in cows looking for a calf that vanished from their vision. Offspring protection is also a kind of maternal investment and may be costly. No sex bias was found in mother-calf distance, vocal contact, or mother's aggression.

According to Lavigueur and Barrette (1992), sex differences in investment ought to be revealed in suckling performance or the growth of calves. Birth weight of European bison male and female calves does not differ (Krasińska and Krasiński 2002) which precludes biased prenatal investment of mothers. Moreover, there are no weight differences between males and females up to at least two years of age (Krasińska and Krasiński 2002) while typical weaning age is about one year (Caboń-Raczyńska et al. 1987). The results of the presented study, together with other research, lead to the conclusion that sex-biased maternal investment does not exist in the European bison.

Acknowledgements: Many thanks to Dr C. Okołów, Director of the Białowieża National Park, for permission to conduct this study. I am indebted to the staff of BNP for facilitating this work, and to those students who helped in the collecting data. I am also very grateful to Prof M. Krasińska, Dr C. C. Gates and two anonymous reviewers for useful comments on the manuscript and S. V. Prior for correcting the English text. The study was partly supported by the State Committee for Scientific Research, Poland, grant 6 P04G 05721. 


\section{References}

Altmann J. 1974. Observational study of behavior. Behaviour 49: 227-267.

Byers J. A. and Moodie J. D. 1990. Sex-specific maternal investment in pronghorn, and the question of a limit on differential provisioning in ungulates. Behavioural Ecology and Sociobiology 26: 157-164.

Caboń-Raczyńska K., Krasińska M., Krasiński Z. A. and Wójcik J. M. 1987. Rhytm of daily activity and behavior of European bison in the Białowieża Forest in the period without snow cover. Acta Theriologica 32: 335-372.

Caley J. M. and Nudds T. D. 1987. Sex-ratio adjustment in Odocoileus: does local resource competition play a role? The American Naturalist 129: 452-457.

Carl G. R. and Robbins C. T. 1988. The energetic cost of predator avoidance in neonatal ungulates: hiding versus following. Canadian Journal of Zoology 66: 239-246.

Cassinello J. 1996. High-ranking females bias their investment in favour of male calves in captive Ammotragus lervia. Behavioural Ecology and Sociobiology 38: 417-424.

Clark A. B. 1978. Sex ratio and local resource competition in a prosimian primate. Science 201: 163-165.

Clutton-Brock T., Albon S. D. and Guiness F. E. 1984. Maternal dominance, breeding success and birth sex ratios in red deer. Nature 308: 358-360.

Clutton-Brock T., Guiness F. E. and Albon S. D. 1982. Red deer, behavior and ecology of two sexes. University of Chicago Press, Chicago: 1-378.

Daleszczyk K. and Krasiński Z. A. 2001. Parturition behaviour of European bison Bison bonasus (L.) living in reserves. Folia Zoologica 50: 75-78.

Egerton P. J. M. 1962. The cow-calf relationship and rutting behavior in the American bison. MSc thesis, University of Alberta, Edmonton: 1-155.

Estes R. D. and Estes R. K. 1979. The birth and survival of wildebeest calves. Zeitschrift für Tierpsychologie 50: 45-95.

Fisher D. O., Blomberg S. P. and Owens I. P. F. 2002. Convergent maternal care strategies in ungulates and macropods. Evolution 56: 167-176.

Geist V. 1971. Mountain sheep. The University of Chicago Press, Chicago: 1-248.

Green W. C. H. 1992a. Social influences on contact maintenance interactions of bison mothers and calves: group size and nearest-neighbour distance. Animal Behaviour 43: 775-785.

Green W. C. H. 1992b. The development of independence in bison: pre-weaning spatial relations between mothers and calves. Animal Behaviour 43: 759-773.

Green, W. C. H. and Rothstein A. 1991. Sex bias or equal opportunity? Patterns of maternal investment in bison. Behavioural Ecology and Sociobiology 29: 373-384.

Hewison A. J. M. and Gaillard J.-M. 1999. Successful sons or advantaged daughters? The Trivers-Willard model and sex-biased maternal investment in ungulates. TREE 14: 229-234.

Kojola I. 1998. Sex ratio and maternal investment in ungulates. Oikos 83: 567-573.

Krasińska M. and Krasiński Z. A. 2002. Body mass and measurements of the European bison during postnatal development. Acta Theriologica 47: 85-106.

Lavigueur L. and Barrette C. 1992. Suckling, weaning, and growth in captive woodland caribou. Canadian Journal of Zoology 70: 1753-1766.

Lent P. C. 1974. Mother-infant relationships in ungulates. IUCN Publications new series 24: 14-55.

Lott D. F. 1974. Sexual and aggressive behavior of adult male American bison (Bison bison). IUCN Publications new series 24: 382-394.

McHugh T. 1958. Social behavior of the American buffalo (Bison bison bison). Zoologica 43: 1-40.

Oftedal O. T. 1985. Pregnancy and lactation. [In: Bioenergetics of wild herbivores. R. J. Hudson and R. G. White, eds]. CRC Press, Inc., Boca Raton, Florida: 215-238.

Pucek Z. P. 1986. Bison bonasus (Linnaeus, 1758) - Wisent. [In: Handbuch der Säugetiere Europas. J. Niethammer and F. Krapp, eds]. Akademische Verlagsgeselschaft, Wiesbaden. Bd. 2/II. Paarhufer-Artiodactyla: 278-315. 
Ralls K., Kranz K. and Lundrigan B. 1986. Mother-young relationships in captive ungulates: variability and clustering. Animal Behaviour 34: 134-145.

Rutberg A. T. 1983. Factors influencing dominance status in American bison cows (Bison bison). Zeitschrift für Tierpsychologie 63: 206-212.

Rutberg A. T. 1986. Lactation and fetal sex ratios in American bison. The American Naturalist 127: 89-94.

Shaw J. H. and Carter T. S. 1989. Calving pattern among American bison. The Journal of Wildlife Management 53: 896-898.

StatSoft. 1984-2003. STATISTICA version 6.1. StatSoft, Inc., Tulsa, USA.

Trivers R. L. and Willard D. E. 1973. Natural selection of parental ability to vary the sex ratio of offspring. Science 179: 90-92.

Walther F. 1979. Das Verhalten der Hornträger (Bovidae). Handbuch der Zoologie 10: 1-184.

Wettemann R. P., Turman E. J., Wyatt R. D. and Totusek R. 1978. Influence of suckling intensity on reproductive performance of range cows. Journal of Animal Sciences 47: 342-346.

Wróblewski K. 1927. [The European bison of Białowieża Primeval Forest]. Wydawnictwo Polskie, Poznań: 1-232. [In Polish]

Received 13 February 2004, accepted 9 September 2004.

Associate Editor was Andrzej Zalewski. 